\title{
Chapter 2 \\ Strategic Analysis and Service Design for Community Policing
}

\author{
Olavi Kujanpää, Pirjo Jukarainen, Jari Taponen, Jarmo Houtsonen, \\ and Vesa Huotari
}

\section{Introduction}

Police services around the world have been in turmoil at the twenty-first century. Structures have been reorganized, budgets cut and reservations expressed about the traditional approaches to policing (e.g. Fyfe et al. 2013). At the same time evidencebased, intelligence-led and increasingly professional approaches have captivated reformers everywhere (e.g. Den Boer 2014). Furthermore, a security architecture, in which the police have played the leading role, seems to be gradually supplemented by a mosaic of security and safety service providers, collaborative arrangements, networks and partnerships (e.g. Hoogenboom 2010). New forms of networks, nodal governance and pluralistic systems (Frevel and Rogers 2016; Shearing and Johnston 2010; White 2011) are viewed as more agile, less costly and more responsive in resolving security problems than the old bureaucratic and centralized forms of governance.

Although the debates about the optimal arrangements for organizing policing are far from conclusive, there is an emerging agreement that policing should become more learning- and problem-oriented and community- and collaboration-based. However, there is uncertainty what these mean in terms of police strategy and daily practice. The purpose of this paper is to highlight what problem-oriented and collaboration-based approach demand from a Community Policing (CP) strategy. To begin with, we introduce different facets of the strategy and discuss how strategic

O. Kujanpää · P. Jukarainen · J. Taponen · J. Houtsonen $(\bowtie) \cdot$ V. Huotari Police University College, Tampere, Finland e-mail: jarmo.houtsonen@polamk.fi 
thinking can be deployed for improving CP services. Next we introduce a concrete tool for the police in building strategic partnerships: a Service Design Canvas for Community Policing that was applied in the Unity project financed by European Commission from its Horizon2020 program during a Finnish pilot exercise. ${ }^{1}$

\section{Community Policing and Aspects of Strategy}

Strategy is regarded useful for CP in three related senses of the term. At the most fundamental level $\mathrm{CP}$ needs strategy to reflect its overall purpose. Next, strategy helps to depict feasible journeys from the present situation to the desired future. In $\mathrm{CP}$ with multiple focus groups and partnerships a whole number of strategic purposes is likely to come up. A challenge is how to make the purposes meet in a fruitful way. Strategy assists in addressing various security issues that concern different communities and collaborative partners. Consequently, CP service design should not be police-centric but interactive. It should be based on information of the various security needs and utilize the analysis of the underlying mechanisms behind the security issues (see Pawson and Tilley 1997). Furthermore, CP should engage partners to search sustainable solutions for these issues.

$\mathrm{CP}$ as a specific way of policing is as much a strategic question as it is tactical and operational task. Strategic design of CP should start from critical analysis of the current position, and the available resources and capabilities, thus helping to make most out of the circumstances. Authorities, such as the police, often understand their purpose rather strictly as something statutory. On the other hand, police is also agile to borrow the latest business management vocabulary, such as being customer oriented, while at the same time resisting, contesting or decoupling any substantive changes in work processes and the scope of tasks (Goodson and Lindblad 2011). Fulfilling the strategic purpose presupposes critical revision of both processes and tasks. This includes a reflection of professional mandates and jurisdictions, and a possibility to re-distribute tasks between other professions or occupations. Often security issues are more than police matters and the analysis of underlying mechanisms may reveal a need for collaborative intervention.

Favoreu et al. (2016) divide three different aspects in the strategy formulation process: rational, political and collaborative. These aspects don't refute each other but vary at different phases of strategy process. Rational approach to strategy emphasizes the effective alignment of goals, targets and means, and suggests that activities are organized and led on the basis of valid situation picture. Political approach points out various interests that individuals and groups carry to strategic planning. In CP collaborative aspect underlies strategy process, which is an opportunity to improve interaction and mutual learning among stakeholders. (see Favoreu et al. 2016).

${ }^{1}$ This paper is based on pilot testing in Finland done within the Unity project funded by the European Commission within the H2020 Framework Programme (Grant Agreement: 653729). 


\section{Unity as a Community Policing Research and Innovation Project}

The fundamental vision of the Unity project was to strengthen the connection between the police and stakeholders to improve the safety and security of communities and citizens. Unity wanted to develop CP concept that is flexible and adaptable to local contexts around Europe. The general idea of CP had to be adjusted to multiple conditions where Unity project conducted pilot testing of its products. ${ }^{2}$ This adaptation required strategic analysis of the current conditions, the needs of the police forces and the communities, and the resources available for the common journey to the desired future. This exercise can utilize widely tested instruments, such as SWOT or PESTEL analysis. The same analytic tools can also be applied on a smaller scale for solving particular security problems undermining the livelihood of communities and the well-being of citizens.

Based on a large survey among the LEAs and stakeholders in eight European countries the Unity project set its goal to improve CP in six outcome areas: (1) trust and confidence, (2) accountability, (3) information sharing and communication, (4) addressing local needs, (5) collaborative problem solving, and (6) crime prevention (proactive policing). Unity project aimed to improve CP in these outcome areas in each pilot context. Important aspect of piloting was also the testing of how Unity technology would help $\mathrm{CP}$ processes to create value in the above-mentioned outcome areas.

\section{Strategy Put into Practice - A Case of Puhos Shopping Center in Helsinki}

One of the Unity pilot cases in Finland was the safety and security situation at an old shopping center in Helsinki. Puhos shopping center is located in a suburb nearby much larger and more modern shopping mall accessed easily by public transportation. When Puhos was opened in 1965, it was the largest of its kind in Finland. Today the old section seems almost empty while most of the business and other activities are in the new section. Enterprises, except for bars, started to move to the modern shopping mall, leaving several business spaces unoccupied. The plot is held by the municipality, but the real estate company is possessed by small-scale owners who have approximately $25 \%$ of shares, of whom a substantial proportion are immigrants, and large corporations who have about $75 \%$ of shares. The property is badly deteriorated and needs urgent renovation. Herein things become complicated, because, first, small-scale owners are afraid that the costs of repair will be far too expensive. Second, small-scale owners are concerned that large corporate owners

\footnotetext{
${ }^{2}$ Besides Finland, the pilot exercise was run in Belgium, Bulgaria, Croatia, Estonia, Germany, Macedonia and the UK.
} 
want to sell the real estate to someone who would pull it down and construct new buildings. Some of the small-scale owners have an idea of developing the company with some investors towards a multicultural shopping mall and service center. The municipality has announced that it won't renew the rental agreement as it ends in 2020; it plans to erect high rise residential area, apart from the old section that is architectural object of protection.

Little by little the open business offices have been acquired by ethnic restaurateurs and various service entrepreneurs and a Muslim prayer house. All these little changes have revitalized the center and gradually strengthened the sense of community and solidarity between entrepreneurs who offer provisions and other services particularly for ethnic customers. Along with the above, specialized social services for diverse groups, such as substance abusers, socially marginalized or isolated people, and immigrant youngsters, were established at the area or nearby by the municipality and non-governmental organizations.

In spring 2016 the police learned through the Somali community that the security situation at the Puhos mall was in decline. Drugs were used quite openly at the mall and the small forest area behind the mall was full of used syringes. Drug addicts peddled stolen goods in public and aggressive collection of drug debts was commonly seen. During the past few years, the area received also more and more vagrants from East Europe. Furthermore, a group of young immigrant men held the mall as their own "territory". They acted violently against white people, especially women. A closer inspection revealed that these young men had arrived in Finland during the early 1990s, after having been lived in the UK during the past decade. Their passports were expired and therefore they had to return to Finland where they did not have any apartments, relatives or other social contacts outside their immediate circle of friends. When running up against problems they did not dare to contact the police or other public authorities.

The prayer house or the mosque at the mall is the largest in the district. The staff does not want to get involved in the troubles outside although these tend to disturb the daily activities at the mosque. The members of the community also assume that talking to authorities would likely entail more nuisance and the security problems would fall upon the activities in the prayer rooms instead of staying outside. The community members tend not to trust the authorities or the impartiality and competence of the police to solve their security problems. Representatives of migrant community have seen that the first challenge is the assumption that the municipality does not value the area and wants to pull it down. Due to the uncertainty of the continuity people are not well motivated to look after and clean the common premises. The second challenge is that many individuals, who loiter there, need support to get back into society, but don't receive the services they need. 


\section{Community Policing in Puhos}

Complex security problems such as the case of Puhos Shopping Center belong to the sphere of activity of the Preventative Policing Unit (PPU) at the Helsinki Police Department. The Unit was established in 2012 as a part of a large organizational reform. The main goal of the PPU is to enhance security in the city of Helsinki: early prevention of phenomena that pose a threat to the security of neighborhoods and the building of partnerships with various stakeholders. In practice this means cooperation with a multitude of actors, such as other local and national police units, public agencies, non-governmental organizations, civic associations and citizens of Helsinki. An essential aspect of the PPU's work is to build and maintain trust among all stakeholders and collectively try to solve possible security challenges. The basic working method is a refined version of problem oriented policing. All teams focus on those security threatening phenomena that require more thorough investigations into the root of the problems, which may not be possible by the more traditional law enforcement methods. By means of local problem solving methods teams try to identify the factors behind crimes and disorder and then move on to influence those circumstances in collaboration with other police units, public agencies, NGOs and residents.

The Puhos case involves agents from both public and private sector and civil society. Therefore the case is difficult for the police to manage. A prerequisite for solving the problems is bringing all relevant stakeholders together and engaging them in improving the security and vitality of the area and its surroundings. Due to the large number of participants the arrangement of meetings and agreeing on schedules and agenda is very challenging. Police would also need to carefully identify the best channels to reach different community groups and stakeholders. For the present, police have communicated with phones and emails, as there is no common digital platform that could be used for exchanging information, booking meetings, or archiving documents. Activities and documents are difficult to manage, because there are so many agencies involved and the problems comprise a complex and intertwined totality. Often half of the major stakeholders have been left out from the meetings; a fact that has increased suspicion among the absentees.

A fundamental challenge has been that there is a lack of shared strategy and prioritization of issues. It has not been clear which agency is in the best position to lead the problem solving process of each individual case. Shared vision and welldefined, likely solvable security challenges can function as motivators that may help bring various agents together on a more permanent basis. In an ideal situation all agencies could have a voice in identifying and prioritizing security issues, exchanging information and experimenting with alternative solutions. Concrete cooperation would improve communication, trust and commitment to seek more sustainable solutions.

The current state of affairs should be improved at least in two respects. First, the problem solving process should be designed to be more systematic, inventive and effective. This requires, for instance, agreed rules for organizing meetings, allocating 
tasks, identifying, analyzing and prioritizing security issues, constructing, testing and evaluating solutions. Second, the problem solving process should be supported by a Collaborative Problems Solving Platform (CPSP), a digital tool and a virtual meeting place to share information, discuss and debate, archive documents, and allow relevant agencies to participate. Platform should help the process management and enable evaluation of impact of activities. This type of platform, including an app and an analytic engine, was developed and piloted within the Unity -project. Although it is a prototype in the making, it was warmly welcomed by the end-users, the police and the other agencies in Helsinki.

\section{Service Design Canvas for Community Policing}

During the Unity project, team at the Police University College (Finland) developed on the basis of business model canvas a strategy tool named a Service Design Canvas for Community Policing (SDCCP). ${ }^{3}$ The tool is for addressing and prioritizing the needs of communities and citizens, setting goals while recognizing how various resources, activities, partners and channels may have an effect on the outcomes. Service Design can be used as an overall strategy tool, or as a more specified tool that suggests actions or programs to solve the individual problems identified by the SWOT analysis or by some other means. In the case of Puhos, this tool was used e.g. to find the added value of $\mathrm{CP}$ and to identify the key partners and channels of communication.

There are nine elements in the SDCCP template. It can be filled by the police or, preferably in collaboration with the community partners, as was the case in Puhos. The first five elements are about the operational environment of CP. At the beginning, the participants should define who are the Key Customers of CP? Which communities, individuals, or neighborhoods will be the key beneficiaries? To whom CP is creating value through solving security problems and increasing safety? This requires thorough discussion and judgement, because customers are known by their problems, but not all problems are police issues.

Next phase requires imagination and innovation. The participants of the local problem solving process, that is, the police and stakeholders alike, should put forward a Unique Value Proposition of CP. What kind of added value are CP activities providing for the communities, neighborhoods or particular individuals? What kind of security or safety needs and expectations should CP meet? The proposed solutions or programs should be accepted by the community, neighborhoods or citizens who will be the recipients of the services. Therefore, it is important that they are also given a voice, directly or indirectly, in the service design process. The third element in the SDCCP is the identification of the main Communication and Contacting Channels with the Key Customers. Through which channels do

${ }^{3}$ The original business model canvas is distributed under a Creative Commons license from Strategyzer AG and can be used without any restrictions for modeling businesses. 
community members want to be reached? Channels could be various types of ICT tools, such as platforms usable by PCs or smartphones, but also the more traditional arenas, such as community meetings and the use of trusted intermediaries. It is useful to consider pros and cons of the ways and tools that are used currently for approaching various community members and individuals. Additionally, one should review how various channels are or could be integrated together, e.g. will there be a joint platform for email, social media and the Internet? Which channels have worked well so far or would likely work in the future? It is also important to consider the aspects of security and cost-efficiency of various options if digital services will be considered for communication and repository.

Fourthly, the users of the service design canvas should analyze the quality and intensity of all significant Customer Relationships. Several questions are relevant here. How would you describe the relationships with the relevant community partners? How would you like to change these relations? How strong is the level of trust between different parties in the collaborative problem solving network? What is the intensity and quality of collaboration and communication between the parties? How well are the police and its practices accepted by different community members? Are the police officers able to reach all the key communities, especially minorities and groups or individuals in a marginal or weak position? Why are some individuals difficult to reach? The final element of the operational environment is the evaluation of Societal Impact of the problem and the benefits that will be received from its successful resolution. The point of departure is the breaking down of the level of crime and disorder within the community. Who are the perpetrators, victims and third parties? How do the citizens perceive the situation, how subjective perceptions of security are related to objective facts? Do the local community partners feel a sense of empowerment and ownership when they can contribute to the problem solving efforts? How do the police officers feel about their work and working conditions? What is the quantity and quality of information and to what extent it is shared between the parties?

After recognizing the needs for security and well-being, one is ready to start designing an operational CP model. This comprises of defining the kKey aActivities, Key Resources and Strategic Partners and finally making a Cost Structure assessment. The sixth phase is to define the Key Activities in CP at large or in relation to individual security issue. What kind of operational policing do the value propositions require? In other words, what needs to be done and how? The next step is defining the Key Resources available for CP. What human, technological, organizational, economic, administrative and legal resources are needed? Resources can include various competencies: skills, knowledge and motivation needed to work for the service of the community. The eighth element is about looking back the Key Communities and considering, who are the key partners of CP in general, or in solving some single issues? Who can help in delivering CP services and finding solutions to problems? Which key resources these partners can bring with them for the benefit of the whole network? Which Key Activities could the partners perform? What would be their specific roles and responsibilities in the collaboration? The final element in the canvas service design is the analysis of the Cost Structure of CP 
with the defined resources, partnerships and activities. How much do alternative resources, activities and communication channels cost? One should compare the cost efficiency of current $\mathrm{CP}$ and the planned working model. Costs and benefits can also be calculated for various kinds of solutions.

The ultimate goal in using the SDCCP is developing value for and with the customers, or rather the partners of the police. The strong point of the tool is that it can be outlined on one page. It can be completed together with stakeholders, and if necessary, be tested and assessed with another group to gain more validity. The feedback from stakeholders and the community members can help assess whether the chosen $\mathrm{CP}$ service design strategy is desirable. The first few CP interventions may be not be perfect, but it is important that stakeholders tolerate some chaos and allow collaborative learning.

\section{Conclusions}

Because at the core of $\mathrm{CP}$ is the collaboration between partners to prevent crime and disorder, and thereby to improve the quality of life and well-being, a wide representative of stakeholders and citizens are invited to co-create solutions. Moreover, $\mathrm{CP}$ is a slow-burn service-oriented style of policing, instead of reactive and control oriented style of law enforcement (Clamp and Paterson 2017). Rather than engaging solely in continuous improvement of their own work, the police should become more adept at sharing experiences and lay knowledge with partners. Bueermann $(2012,19)$ predicts that in the future police will be more and more a broker and a facilitator for community action to solve problems related to crime and disorder. The role of citizens and civic associations will change from mere consumers to partners and co-producers who will add their local knowledge, skills and resources to the production of security services. As security becomes public good that is coproduced through various networks and actors, the police should increase their understanding of the joint processes this involves. This article aimed at offering such understanding by discussing about perspectives and tools for improving $\mathrm{CP}$ services. More specifically, the paper described one practical tool: Service Design Canvas for Community Policing, which could be advantageous for constructing the overall strategy for community police, or just trying to collaboratively solve local security issues with the communities and citizens.

\section{References}

Bueermann, J. (2012). Preparing the police for an uncertain future: Four guiding principles. In D. R. Cohen McCullough \& D. L. Spence (Eds.), American policing in. 2022: Essays on the Future of a Profession. COPS, U.S. Department of Justice. http://ric-zai-inc.com/Publications/ cops-p235-pub.pdf. Accessed 23 Nov 2017. 
Clamp, K., \& Paterson, C. (2017). Restorative policing. Concepts, theory and practice. Abingdon: Routledge.

Den Boer, M. (2014). Intelligence-led policing in Europe. Lingering between idea and implementation. In I. Duyvesteyn, B. de Jong, \& J. van Reijn (Eds.), The future of intelligence: Challenges in the $21^{\text {st }}$ century. London: Routledge.

Favoreu, C. D., Carassus, D., \& Maurel, C. (2016). Strategic management in the public sector: A rational, political or collaborative approach? International Review of Administrative Sciences, 82(3), 435-453. https://doi.org/10.1177/0020852315578410.

Frevel, B., \& Rogers, C. (2016). Community partnerships (UK) vs Crime Prevention Councils (GER): Differences and similarities. Police Journal: Theory, Practice and Principle., 89(2), 133-150. https://doi.org/10.1177/0032258X16641426.

Fyfe, N., Terpstra, J., \& Tops, P. (2013). Centralizing forces? Comparative perspectives on contemporary police reforms in northern and Western Europe. Hague: Eleven.

Goodson, I. F., \& Lindblad, S. (2011). Conclusions: Developing a conceptual framework for understanding professional knowledge. In I. F. Goodson \& S. Lindblad (Eds.), Professional knowledge and educational restructuring in Europe. Rotterdam: Sense Publishers.

Hoogenboom, B. (2010). The governance of policing and security - Ironies, myths and paradoxes. Basingstoke: Palgrave MacMillan.

Pawson, R., \& Tilley, N. (1997). Realistic evaluation. London: Sage.

Shearing, C., \& Johnston, L. (2010). Nodal wars and network fallacies. Theoretical Criminology, 14(4), 1362-4806.

White, A. (2011). The new political economy of private security. Theoretical Criminology, 16(1), 85-101. https://doi.org/10.1177/1362480611410903.

Open Access This chapter is licensed under the terms of the Creative Commons Attribution 4.0 International License (http://creativecommons.org/licenses/by/4.0/), which permits use, sharing, adaptation, distribution and reproduction in any medium or format, as long as you give appropriate credit to the original author(s) and the source, provide a link to the Creative Commons license and indicate if changes were made.

The images or other third party material in this chapter are included in the chapter's Creative Commons license, unless indicated otherwise in a credit line to the material. If material is not included in the chapter's Creative Commons license and your intended use is not permitted by statutory regulation or exceeds the permitted use, you will need to obtain permission directly from the copyright holder. 